\title{
The Evolution of Home Mechanical Ventilation in Poland Between 2000 and 2010
}

\author{
Jacek Nasiłowski MD PhD, Mariusz Wachulski MD, Wojciech Trznadel MD, \\ Witalij Andrzejewski MD, Marek Migdał MD PhD, Wojciech Drozd MD, Andrzej Pytel MD, \\ Robert Suchanke MD, Małgorzata Czajkowska-Malinowska MD PhD, Tomasz Majszyk MD, \\ Zbigniew Szkulmowski MD PhD, and Ryszarda Chazan MD PhD
}

\begin{abstract}
BACKGROUND: Home mechanical ventilation (HMV) is a routine method of treatment for patients with chronic ventilatory failure. Over the last $20 \mathrm{y}$, a marked development in HMV has been noted in terms of its prevalence and the changing proportion of patients with various indications. However, data on HMV come exclusively from the developed countries of Europe and North America. Nowadays, we can see the emergence of HMV in less developed countries. This study aimed to describe the development of HMV in Poland. METHODS: Data from the largest HMV centers were retrospectively evaluated with regard to cause of respiratory failure, ventilation technique, and characteristics of the HMV-implementing institution. RESULTS: The number of subjects treated with HMV increased from 8 in 2000 to 928 in 2010. Neuromuscular diseases remained the main indication. However, their relative contribution decreased from 100 to $51 \%$ in favor of pulmonary diseases (an increase from 0 to $21 \%$ ) and hypoventilation syndromes $(0 \%$ in 2000 and $11 \%$ in 2010). The majority of the HMV population treated between 2000 between 2008 was ventilated by tracheostomy; however, since 2007 , the percentage of subjects on noninvasive ventilation significantly increased and was equal to the number of tracheostomized subjects. HMV was initiated mainly in ICUs. However, their role systematically diminished, and an increasing number of subjects were recruited in respiratory departments. CONCLUSIONS: The prescription pattern of HMV in Poland has evolved, and there is a clear shift from neuromuscular to respiratory diseases. The prevalence of ventilation via tracheostomy still remains very high in comparison with other European countries. The Polish experience could be useful for countries with emerging HMV care systems. Key words: chronic respiratory failure; epidemiology; home mechanical ventilation; noninvasive ventilation; invasive ventilation. [Respir Care 2015;60(4):577-585. (C) 2015 Daedalus Enterprises]
\end{abstract}

\section{Introduction}

Home mechanical ventilation (HMV) is a well-established method of treatment for patients with chronic ven- tilatory failure. The worldwide development of HMV began in the 1980s. ${ }^{1}$ The main method of ventilation at that time was volume cycled ventilation via tracheostomy. ${ }^{2,3}$ Negative-pressure ventilation was an alternative method. ${ }^{4}$

\footnotetext{
Dr Nasiłowski and Chazan are affiliated with the Department of Internal Medicine, Pneumology and Allergology, Medical University of Warsaw, Warsaw, Poland. Dr Wachulski is affiliated with the Home Mechanical Ventilation Center, Dom Sue Ryder, Bydgoszcz, Poland. Dr Trznadel is affiliated with Home Mechanical Ventilation Center, VentaMed, Zielona Góra, Poland. Dr Andrzejewski is affiliated with the Lodz Hospice for Children, Łódź, Poland. Dr Migdał is affiliated with the Pediatric Intensive Care Unit, Children's Memorial Health Institute, Warsaw, Poland. Dr Drozd is affiliated with the Home Mechanical Ventilation Center,
}

\footnotetext{
BetaMed, Katowice, Poland. Drs Pytel and Suchanke are affiliated with the Home Mechanical Ventilation Center, HELP, Poznań, Poland. Dr Czajkowska-Malinowska is affiliated with the Department of Pulmonary Diseases and Respiratory Failure, Kuyavian-Pomeranian Regional Pulmonology Centre, Bydgoszcz, Poland. Dr Majszyk is affiliated with Home Mechanical Ventilation Center, St Vincent Medical Center, Warsaw, Poland. Dr Szkulmowski is affiliated with the Home Ventilation Center, Medycyna Specjalistyczna, Bydgoszcz, Poland.
} 
Although more physiologic, this method had some major disadvantages and was too cumbersome to be widely used. The first beneficiaries of HMV were patients with primary impairment of the ventilatory pump due to neuromuscular diseases and restrictive chest-wall disorders. ${ }^{5-7}$

Technological developments of ventilators and interfaces in the 1990s allowed a wider application of noninvasive ventilation (NIV), and thus, ventilatory support became more acceptable for the patient and easier for the physician. In adults, ventilation via tracheostomy was almost completely replaced by NIV. ${ }^{1}$ This method improves quality of life and helps to avoid some complications related to an invasive approach. ${ }^{8}$ The advantages of NIV and concomitant advances in the diagnosis of sleep medicine resulted in broad institution of HMV not only after an acute episode, but also mainly electively in the course of disease. At the same time, some epidemiological factors significantly affected the HMV population. Aging of the population, ${ }^{9}$ rising prevalence of obesity, ${ }^{10,11}$ and COPD (www.goldcopd.com. Accessed April 24, 2013) resulted in an increased number of patients with chronic respiratory failure. A substantial increase in the number of patients treated with HMV was noted in the 1990s..$^{12-14}$ In 2001, the prevalence of HMV was estimated as 6 patients $/ 100,000,{ }^{1}$ and this number further increased to $16-20$ patients $/ 100,000$ in 2009. ${ }^{15}$ This increase was associated with a distinct shift in underlying diseases from neuromuscular and restrictive lung diseases to obesity hypoventilation syndrome ${ }^{16}$ and end-stage COPD. ${ }^{14,17}$

Almost all data on HMV published to date come from well-developed areas around the world: United States, ${ }^{5}$ Western European countries, ${ }^{1,2,12,14,15}$ Australia and New Zealand, ${ }^{16}$ and Hong Kong. ${ }^{18}$ Data about HMV in other countries are scarce. The largest pan-European survey of HMV was published in 2005, providing data from 13 countries. Poland was the only country from the former Eastern Bloc and reported only 40 patients (with half of them being ventilated for $<1 \mathrm{y}$ ), which gave a prevalence of 0.1 patient/100,000. ${ }^{1}$ Almost all of these patients had neuro-

Dr Nasiłowski has disclosed a relationship with ResMed and Philips. The other authors have disclosed no conflicts of interest.

Dr Nasiłowski presented a version of this paper at the 13th International Conference on Home Mechanical Ventilation, held March 15-17, 2012, in Barcelona, Spain; the ERS International Congress, held September 1-5, 2012, in Vienna, Austria; and the Polish Respiratory Society Congress, held May 12-15, 2012, in Wisła, Poland.

Correspondence: Jacek Nasiłowski MD PhD, Department of Internal Medicine, Pneumology and Allergology, Medical University of Warsaw, Banacha Street, 02-097 Warsaw, Poland. E-mail: jnasilowski@ wum.edu.pl.

DOI: $10.4187 /$ respcare. 03126

\section{QUICK LOOK}

\section{Current knowledge}

Home mechanical ventilation (HMV) is a routine method of treatment for patients with chronic ventilatory failure. In the last 2 decades, HMV use has increased significantly, with the largest increase seen in noninvasive ventilation for neuromuscular disease. The use of HMV in less developed countries appears to be increasing.

\section{What this paper contributes to our knowledge}

The prescription pattern of HMV in Poland has evolved with a shift from support of patients with neuromuscular disease to primary respiratory diseases. The prevalence of ventilation via tracheostomy remains high in comparison with other European countries.

muscular diseases and were tracheostomized. Data from Poland were considered as representative of other countries from Central and Eastern Europe. ${ }^{19}$ More recent data from 2008/2009 showed that the prevalence of HMV in Poland was 2.2 patients $/ 100,000$, with a marked number of patients with neuromuscular diseases $(80 \%)$ and a dominant technique of invasive ventilation $(60 \%){ }^{20}$

The aim of the study was to analyze data on HMV in one of the developing European countries. We intended to describe the trends in HMV in Poland over the last decade, focusing on the causes of chronic respiratory failure, ventilation technique, and type of institution where ventilatory support was initiated.

\section{Methods}

\section{Definitions}

HMV was defined as volume or pressure cycled support ventilation delivered by positive pressure via a tracheostomy or a noninvasive interface. Subjects treated only with CPAP were not considered as HMV. As far as we know, in Poland, there are no patients treated with negative-pressure ventilation.

The HMV subject was defined as a patient who had been treated with temporal or continuous mechanical ventilation for at least $6 \mathrm{~h} / \mathrm{d}$ and stayed at home under family care. Patients from chronic care institutions were not included in the survey. According to our knowledge, institutionalized patients comprise a very low proportion of patients ventilated outside hospitals as a result of the low number of such centers in Poland.

The site of HMV initiation was defined as an in-patient or out-patient setting where subjects stayed when the need 
for prolonged ventilation was established as appropriate, followed by titration of ventilator settings, choosing the most adequate interface, and training the subject and caregivers. Because no commonly accepted guidelines on weaning from mechanical ventilation and indications for HMV were available, the decision on initiation of HMV was always left to the discretion of the treating physician.

\section{Center Identification}

We arbitrarily selected institutions that managed at least 40 patients and had at least a 5-y experience with HMV. The selected institutions provided treatment for the vast majority $(\sim 90 \%)$ of all patients ventilated at home in Poland. HMV provided by all centers was funded by Public National Health Funds. Uniform rules for HMV care for all patients were established by the Ministry of Health and were described in a previous publication. ${ }^{20} \mathrm{We}$ distinguished regional centers, which provided HMV in only one administrative province (voivodeship), and multiregional centers, which provided HMV in more than one voivodeship.

\section{Study Design}

In September 2011, a questionnaire designed specifically for the purpose of the study was sent to the heads of the eligible institutions. Every center was asked to provide medical data of their HMV subjects, covering the period between 2000 and 2010. All completed surveys were returned by May 2012.

The study protocol was approved by the institutional review board. Because no interventions were performed and no individual data were analyzed, the need for informed consent was waived.

\section{Survey Content}

The first part of the questionnaire included general questions about center details: location, area of activity (uniregional or multiregional), and year of initiating HMV. The second part consisted of 4 sections containing questions about the number of subjects treated with HMV in each consecutive year between 2000 and 2010. The first section concerned the overall number of treated subjects, divided into 5 disease categories: 1) neuromuscular diseases, 2) lung diseases (COPD, bronchiectasis, cystic fibrosis, interstitial diseases), 3) chest-wall diseases (scoliosis, thoracoplasty, ankylosing spondylitis, post-tuberculosis sequelae), 4) hypoventilation syndromes (due to obesity, central congenital hypoventilation syndrome, central sleep apnea), and 5) other diseases that were not included in the first 4 groups. The second section was devoted to the technique of ventilation (invasive and noninvasive) and
Table 1. Characteristics of the HMV Centers in Poland

\begin{tabular}{|c|c|c|c|c|c|}
\hline \multirow[b]{2}{*}{ Center } & \multirow{2}{*}{$\begin{array}{l}\text { Area of Activity/ } \\
\text { No. of Provinces }\end{array}$} & \multirow{2}{*}{$\begin{array}{l}\text { Year of } \\
\text { Start of } \\
\text { HMV }\end{array}$} & \multicolumn{3}{|c|}{ Subjects $(n)$} \\
\hline & & & $\begin{array}{c}\text { Invasive } \\
\text { Ventilation }\end{array}$ & NIV & Total \\
\hline 1 & Regional/1 & 1999 & 3 & 71 & 74 \\
\hline 2 & Regional/1 & 1999 & 26 & 44 & 70 \\
\hline 3 & Multiregional/3 & 2000 & 81 & 5 & 86 \\
\hline 4 & Multiregional/11 & 2003 & 205 & 185 & 390 \\
\hline 5 & Multiregional/4 & 2003 & 78 & 82 & 160 \\
\hline 6 & Regional/1 & 2004 & 63 & 20 & 83 \\
\hline 7 & Regional/1 & 2004 & 22 & 25 & 47 \\
\hline 8 & Multiregional/7 & 2004 & NA & NA & 423 \\
\hline 9 & Multiregional/5 & 2006 & 88 & 76 & 162 \\
\hline Total subjects, $n$ & & & 566 & 508 & 1,495 \\
\hline \multicolumn{6}{|c|}{$\begin{array}{l}\text { HMV = home mechanical ventilation } \\
\text { NIV = noninvasive ventilation } \\
\text { NA = data not available }\end{array}$} \\
\hline
\end{tabular}

included queries about the number of new cases and the overall number of subjects treated with NIV or tracheostomy. The third section gathered data on the age of the treated subjects (adults and children), and the questions in the last section referred to the site where ventilation was initiated: ICU, respiratory department, neurology department, general medicine department, home, or other.

\section{Results}

\section{HMV Centers}

Nine HMV centers fulfilled the eligibility criteria, and all returned a completed questionnaire. However, quality assessment revealed numerous missing data in one questionnaire. These data could not be completed as a consequence of the lack of data in the center's records. The missing data concerned the first section (diagnosis; only new subjects every year were reported instead of all subjects treated every year) and the entire second section (technique of ventilation). Therefore, those data were not included in the results shown for prevalence and diagnostic groups. Two centers started HMV in 1999, one in 2000, two in 2003, three in 2004, and one in 2006. The mean center experience was $9 \pm 3$ y (range of 6-13 y). One center was dedicated specifically to children, two centers were dedicated solely to adults, and other centers treated subjects irrespective of age. Five centers (56\%) were multiregional. Details of the data from the individual centers are presented in Table 1.

\section{Subjects}

All centers reported data regarding 1,495 subjects treated between 2000 and 2010. In 2000, there were only 8 sub- 


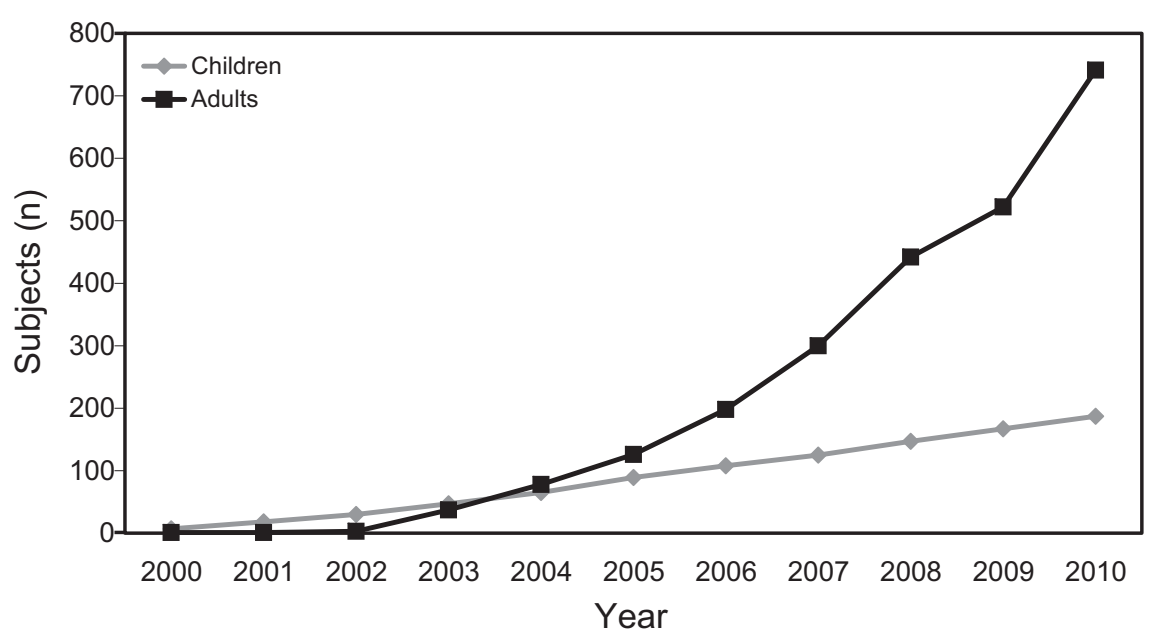

Fig. 1. The number of adults and children treated with home mechanical ventilation in Poland in the surveyed centers.

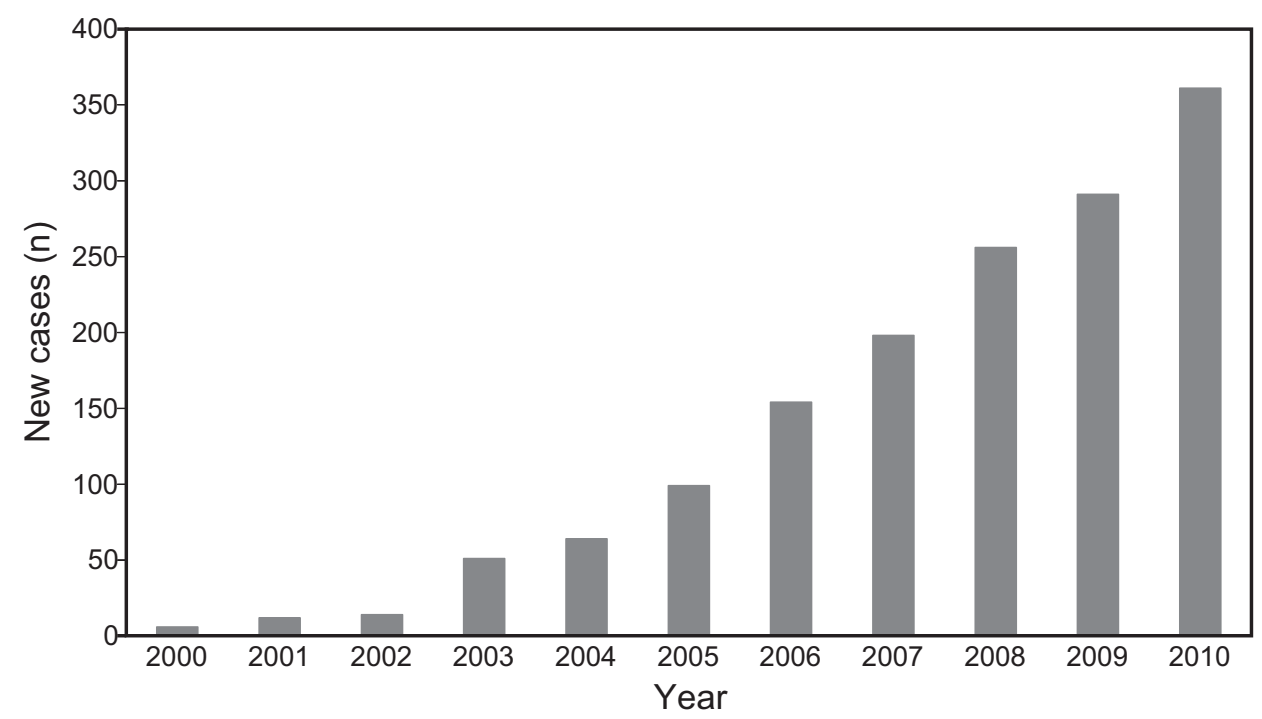

Fig. 2. Number of new cases of subjects treated with home mechanical ventilation in Poland in the surveyed centers.

jects ( 7 children), and in 2010, there were 928 subjects (187 children, 20\%). Between 2000 and 2002, children formed the vast majority of HMV subjects (88-95\%). Since 2003, the percentage of children progressively decreased as a result of rapid growth of the population of treated adults, and in 2010, children accounted only for $20 \%$ of the total number of HMV subjects (Fig. 1).

The number of new cases stabilized at a level of $\sim 10$ subjects/y between 2000 and 2002. Thereafter, it increased to 50 subjects/y in the following $2 \mathrm{y}$. Since 2005 , the number of new subjects increased systematically by $\sim 50$ subjects/y. The largest progress was noted in the last year of the study and reached an increase of 70 subjects compared with the previous year. The trend in the number of new cases is shown in Figure 2.
Because the collected data include the majority ( $90 \%)$ of all treated patients in Poland, we estimated the approximate prevalence of HMV use. In 2010, it reached almost 2.5 subjects/100,000 of the general population. The change in prevalence over time is shown in Figure 3.

The majority of subjects on HMV in Poland suffered from neuromuscular diseases. This preponderance persisted over the whole study period. However, it gradually decreased from almost $100 \%$ between 2000 and 2002 to $51 \%$ in 2010. The decreasing contribution of neuromuscular diseases was a consequence of the increase in the number of subjects with pulmonary diseases and, to a lesser extent, with hypoventilation syndromes. The first subjects with a diagnosis of respiratory failure due to pulmonary conditions appeared in 2004, and the number of subjects rapidly 


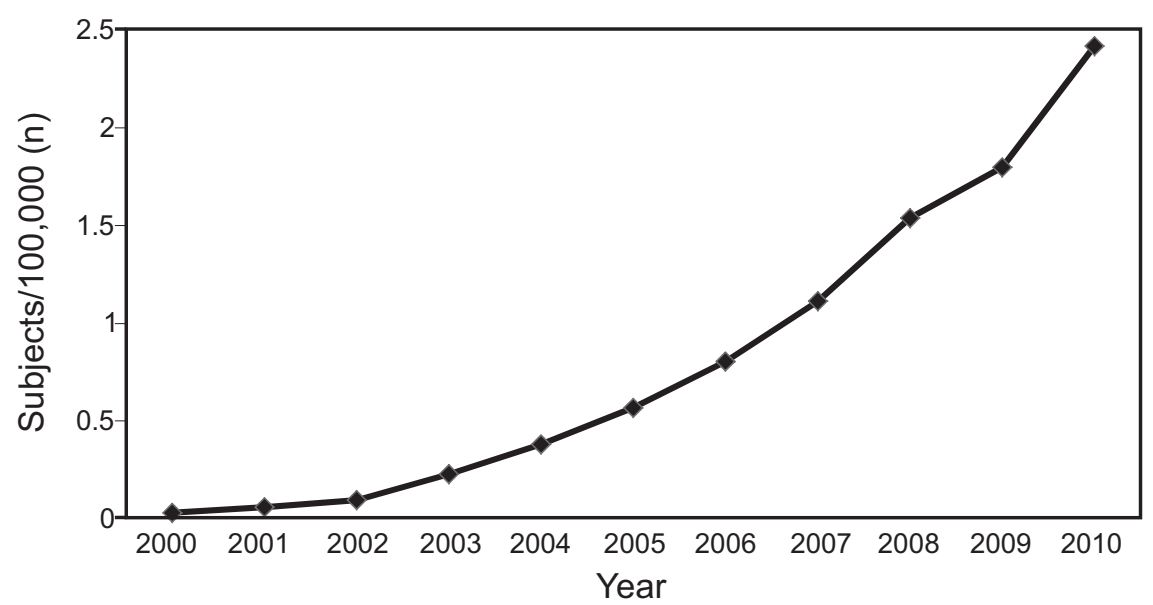

Fig. 3. The prevalence of home mechanical ventilation in Poland in the consecutive years based on data from surveyed centers. Note that results are slightly understated (see explanation in text).

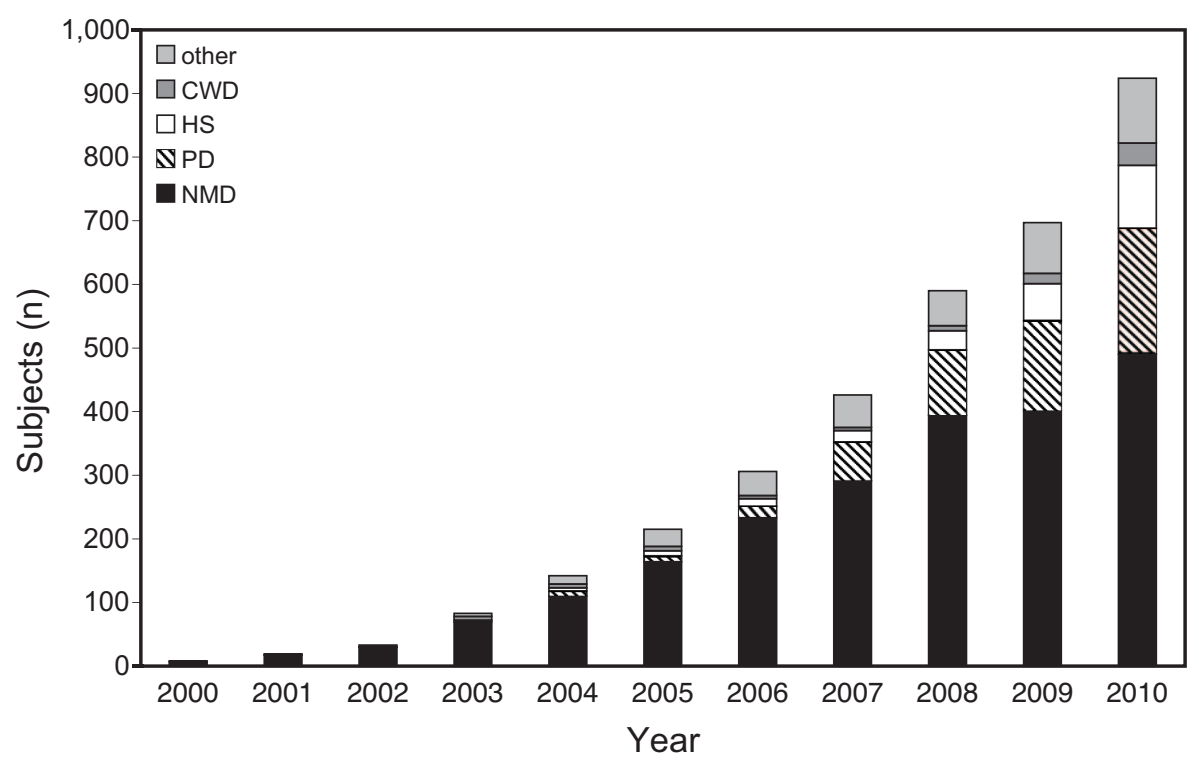

Fig. 4. Number of subjects on home mechanical ventilation in Poland according to diagnostic group, with data from 8 centers. CWD $=$ chestwall diseases; HS = hypoventilation syndromes; PD = pulmonary diseases; NMD = neuromuscular diseases.

increased beginning in 2007. In 2010, they accounted for almost $25 \%$ of all HMV cases. Hypoventilation syndromes were the third main diagnostic group. The percentage remained at a level of $4 \%$ until 2008 , when it started to increase, reaching $11 \%$ in 2010 . The proportion of chest-wall diseases remained very low at $\sim 3 \%$ and did not change during the last decade. The increase in the number of HMV subjects within the diagnostic groups is shown in Figure 4.

\section{Technique of Ventilation}

In 2000 and 2001, ventilation via tracheostomy was exclusively used. The first subjects on NIV were treated in
2002. The number of subjects on NIV reached one third in 2004 and then leveled off for the following $5 \mathrm{y}$, followed by a rapid increase until 2010, when the proportions of subjects treated with NIV and tracheostomy equalized. Since 2008, the number of new cases treated noninvasively surpassed the number of new cases treated with invasive ventilation (see Fig. 5), and in 2010, the total number of subjects in both groups was virtually the same.

\section{Setting of HMV Initiation}

In $60 \%$ of all treated subjects, ventilation was started in the ICU setting. Between 2000 and 2002, all HMV sub- 


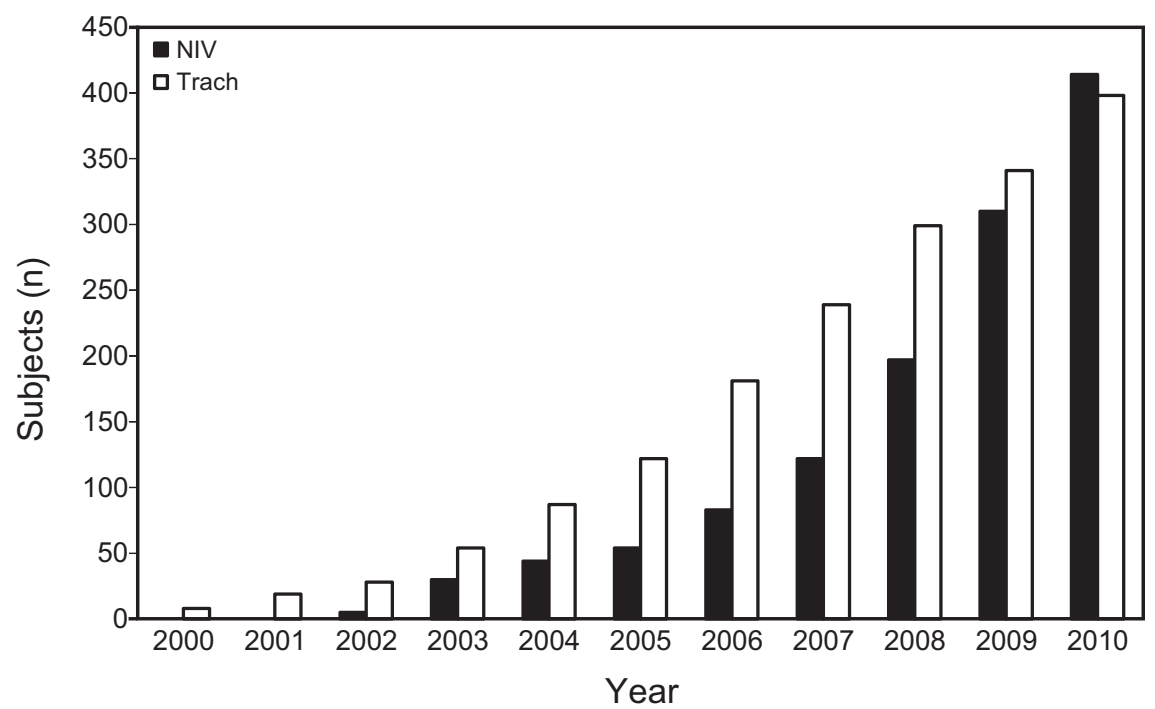

Fig. 5. Number of subjects on home mechanical ventilation in Poland according to the technique of ventilation, with data from 8 centers. NIV = noninvasive ventilation; Trach = invasive ventilation via tracheostomy.

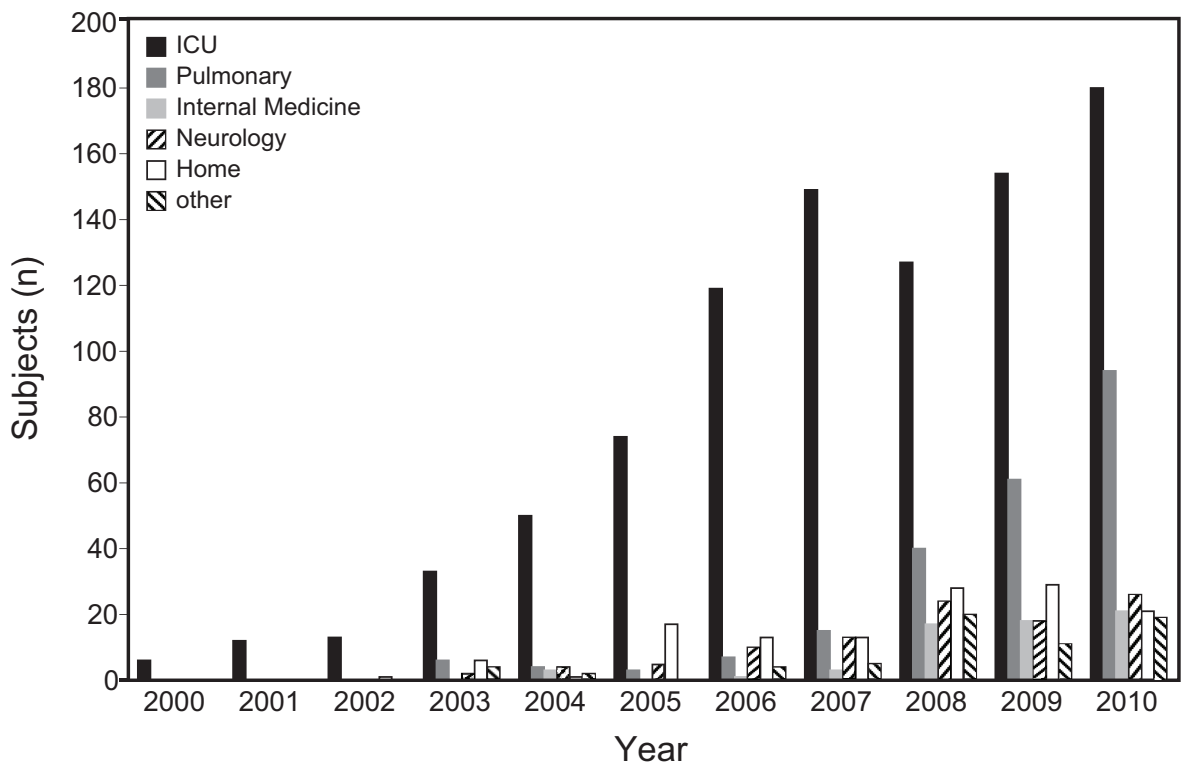

Fig. 6. Number of subjects using home mechanical ventilation according to the site of initiation.

jects came from the ICU. In 2003, the first subjects were received treatment in other settings, mostly pulmonary departments or at home. Since 2007, the number of HMV cases initiated in pulmonary departments gradually increased. In 2010, 46\% of new subjects started HMV in the ICU and $35 \%$ in pulmonary departments. Over the entire decade, initiation of HMV in neurology and general medicine departments and at home remained relatively stable at $6 \pm 3 \%, 4 \pm 3 \%$, and $9 \pm 5 \%$, respectively. Details concerning the site of HMV initiation are presented in Figure 6.

\section{Discussion}

To our knowledge, this is the first HMV survey coming from an Eastern and a Central European country. We managed to obtain data from all large centers working in this field for a mean period of $9 \pm 3 \mathrm{y}$. A total of 1,495 subjects were analyzed. We demonstrated a $>100$-fold increase in the number of HMV subjects over $11 \mathrm{y}$, from 8 subjects treated in 2000 to 928 subjects in 2010. Such a striking result has not been reported in any previous survey. The French Register showed a 10-fold increase from 
180 subjects in 1988 to 1,800 subjects in $1998 .{ }^{13}$ Analysis of data from the Swedish National Register ${ }^{21}$ and Swiss Regional Register ${ }^{14}$ indicated a similar net annual increase of $\sim 10 \%$. A similar 10 -fold increase was noted in the northern Netherlands but over a longer time period (19802004). ${ }^{22}$ The most significant increase in HMV use in developed countries took place in the 1990s. In the first decade of the 21 st century, the increase was still preserved, but was much slower, reaching an annual 2-3-fold increase. ${ }^{15}$

In Poland, HMV was occasionally used in the 1990s. At that time, it was not funded by public resources. Only a few patients, mainly children, were ventilated with devices donated by charity foundations or foreign countries or, very rarely, purchased by families. ${ }^{23}$ In $2000-2003$, a pilot pediatric program enabling sponsorship of the devices for children was introduced by the Ministry of Health. ${ }^{24}$ The cornerstone of the development of HMV use in Poland was the establishment of regulations of HMV patient care by the Ministry of Health in 2004. Simultaneously, the National Health Fund started to reimburse for HMV from the public health budget. Since then, we observed a rapid increase in the number of patients and new health centers dedicated to HMV.

The most striking difference between the pattern of HMV use in Poland and more developed countries is the type of ventilation. In the latter, subjects treated with invasive ventilation are a diminishing minority. According to data gathered in early 1990s in a single-center register in California, tracheostomized subjects accounted for $76 \%$ of HMV cases, ${ }^{25}$ whereas the Swedish National Register documented $25 \%$ of tracheostomized cases before $1996^{21}$ and only $6 \%$ in the following $10 \mathrm{y} .{ }^{26} \mathrm{~A}$ pan-European survey (Eurovent) presenting data from 2001 to 2002 revealed only $13 \%$ of tracheostomized subjects. ${ }^{1}$ The most recent survey from Australia and New Zealand estimated the proportion of tracheostomized subjects as $3 \% .{ }^{16}$ The frequent use of invasive ventilation in Poland could be partly explained by the high number of neuromuscular patients. The Eurovent study showed that as many as $24 \%$ of subjects with neuromuscular diseases were tracheostomized, whereas only $8 \%$ of subjects with lung diseases and $5 \%$ of those with thoracic deformations were tracheostomized. ${ }^{1}$ However, in some countries, including The Netherlands, the percentage of neuromuscular patients is as high as $59 \%$, and invasive ventilation is used only in $18 \%$ of all patients (personal communication, 2012, Mike Kampelmacher MD, Medical University of Utrecht, Utrecht, The Netherlands).

Notwithstanding, the high percentage of invasive ventilation use in Poland cannot be explained only by the high number of patients with neuromuscular diseases. Apparently, the main reason is the timing of HMV initiation. According to regulations of the Ministry of Health, every patient had to be qualified exclusively by a specialist in intensive care medicine. The main idea of creating the HMV system in Poland was to release beds in ICUs, which were continually occupied by chronically ventilated patients. This system was not available for stable patients who had symptoms of hypoventilation and had not experienced an acute episode. Laub and Midgren ${ }^{26}$ reported that subjects who had started HMV in an acute setting were more likely to be ventilated via tracheostomy than subjects qualified electively. Moreover, the long-term retrospective observational study performed by Duiverman et $\mathrm{al}^{22}$ suggested a worse prognosis for subjects in whom HMV was implemented on an acute basis. In Poland, a rapid decrease in the proportion of tracheostomized subjects began in 2007 due to the increased number of HMV cases initiated in respiratory departments.

In contrast to Western European surveys, the Polish study demonstrated a notable predominance of subjects with neuromuscular diseases. Despite a 2 -fold decrease in the proportion of subjects with neuromuscular diseases versus subjects with pulmonary diseases and hypoventilation syndromes, neuromuscular diseases were still the most frequent indication for HMV in 2010.

Pan-European data demonstrated that subjects with neuromuscular diseases accounted for one third of all HMV subjects in $2001^{1}$ and $20-25 \%$ in $2009 . .^{27}$ In some countries (Denmark and The Netherlands), the number of chronically ventilated subjects with neuromuscular diseases was relatively high. In The Netherlands, these subjects accounted for 51-63\% HMV cases depending on the center (personal communication, 2012, Mike Kampelmacher MD, Medical University of Utrecht, Utrecht, The Netherlands).

The need for ventilatory support in patients with neuromuscular disorders is rather obvious; lack of mechanical ventilation translates easily to a very poor prognosis. This may, at least to some extent, explain the relatively high proportion of these patients among subjects treated with HMV in various countries, particularly in those with lower medical care expenses. Indications for HMV and its impact on prognosis in pulmonary disorders, such as $\mathrm{COPD}^{17,28}$ or cystic fibrosis, ${ }^{29}$ are a matter of ongoing discussion.

The very low proportion of subjects with chest-wall disorders in our register ( $\sim 3 \%$ throughout the entire decade) is an unexpected finding. Poland had a relatively high incidence of tuberculosis in the second half of the 20 th century ${ }^{30}$; one would expect that this may have resulted in numerous post-tuberculosis complications deforming the thoracic cage. We believe that most of the patients with chest-wall disorders in Poland are managed in long-term oxygen therapy (LTOT) centers and treated with oxygen alone. This shows the need for further development of HMV, as studies in this population clearly in- 
dicate a significantly better prognosis in the group treated with HMV compared with LTOT. 31,32

The low percentage of subjects with hypoventilation syndromes, mainly obesity hypoventilation syndrome, is another marked difference between the pattern of HMV indications in Poland and other countries. In our survey, the number of hypoventilation syndrome cases remained below 5\% until 2007, when they started to steadily increase, reaching $11 \%$ in 2010 . This is comparable with data from the Dutch Register showing that subjects with hypoventilation syndromes accounted for $4 \%$ of HMV cases (personal communication, 2012, Mike Kampelmacher MD, Medical University of Utrecht, Utrecht, The Netherlands). This is in contrast to reports from other European countries. In Switzerland, this subgroup was dominant since the end of the 1990s and accounted for one third of all treated subjects between 1990 and 1999.14 A similar percentage was found in more recent surveys from Scandinavia, ${ }^{26}$ France, ${ }^{27}$ and Australia and New Zealand. ${ }^{16}$ In all studies, obesity hypoventilation syndrome was the leading cause of respiratory failure. In Poland, patients with obesity hypoventilation syndrome are treated mainly with CPAP only or with CPAP and LTOT when applicable. ${ }^{33}$ However, since 2007, an increasing number of patients with hypoventilation syndromes are being treated with HMV, which could be a result of a growing awareness of chest physicians and greater access to sleep laboratories. ${ }^{34}$

Depending on the nature of the underlying disease and its course, patients with chronic respiratory failure may require different treatment modalities (HMV, LTOT, CPAP). It seems that optimal management could be offered by institutions that have experience with these methods. In Poland, centers dedicated to the treatment of respiratory failure usually focus on a single method, and this may limit access to adequate treatment. In France, the management of patients with chronic respiratory failure is provided by centers that offer complex care and is supervised by a national organization. ${ }^{2}$ This is a good future direction for countries that are developing their model of care for such patients and enables optimal treatment of chronic respiratory failure.

Beginning in 2007, the number of subjects with pulmonary diseases treated with HVM has increased rapidly, and in 2010 , it reached $21 \%$. This may be attributed to the growing awareness of chest physicians regarding the need for such therapy or to the development of NIV. Comparison of the evolution of this population in Poland with that in other countries is difficult due to lack of data. In the Eurovent study, the proportions of subjects with pulmonary pathologies treated with HMV ranged from 10 to $50 \% .{ }^{1}$

On the whole, the percentage of patients with pulmonary disorders (mainly COPD) in Poland and developed countries in Europe does not differ significantly. In a sur- vey by Veale et al, ${ }^{27}$ this group accounted for $24 \%$. However, outside Europe, the reported data differ significantly. In Australia and New Zealand, lung pathologies account for $13 \%$ of HMV cases, ${ }^{16}$ whereas in Hong Kong, the percentage is $49 \%$, with lung pathology being the most frequent indication for HMV in this region. ${ }^{18}$

Children constitute a large group of patients treated with HMV in Poland. Until introduction of national funding in 2004, the number of children on HMV was higher than that of adults. Within the following years, their proportion systematically decreased due to a rapidly growing number of included adults. In 2010, children accounted for $20 \%$ of HMV cases. Most European surveys did not include children. ${ }^{1,26}$ Midgren et al21 reported interesting differences in age distribution of HMV subjects in Sweden and Denmark in the mid-1990s. Subjects $<20$ y of age composed almost half of the Danish HMV population and $\sim 10 \%$ of the Swedish HMV population. Differences in age were accompanied by differences in the pattern of indications and the system of organization of HMV care. The Danish model focused on young subjects with neuromuscular diseases, and HMV was managed by anesthesiologists. According to data from The Netherlands, subjects $<20$ y of age accounted for $11 \%$ of the population treated with HMV (personal communication, 2012, Mike Kampelmacher MD, Medical University of Utrecht, Utrecht, The Netherlands).

\section{Conclusions}

In summary, the development of HMV in Poland was delayed in comparison with that of more developed countries. Within the first years, it differed from common European practice, mainly due to a very high proportion of tracheostomized patients and very few patients with pulmonary disorders and hypoventilation syndromes. The main concerns of the Polish system are the lack of centers offering complex treatment of patients with chronic respiratory failure and the small contribution of pulmonologists to the process of HMV use. We believe that the Polish experience not only broadens the knowledge of HMV care systems, but also may give useful information to those countries that are planning to institute HMV.

\section{ACKNOWLEDGMENTS}

We thank Ms Beata Drzazga (BetaMed HMV Center, Katowice, Poland) for her contribution to subject data. We thank Professor J Zieliński, Dr Marta Warzȩchowska-Maskey, and Professor Rafał Krenke (Department of Internal Medicine, Pneumology and Allergology, Medical University of Warsaw, Warsaw, Poland) for their constructive comments on this manuscript. We give special thanks to Dr Mike Kampelmacher, who provided very relevant data from the register of patients with HMV in The Netherlands.

\section{REFERENCES}

1. Lloyd-Owen SJ, Donaldson GC, Ambrosino N, Escarabill J, Farre R, Fauroux B, et al. Patterns of home mechanical ventilation use in 
Europe: results of the Eurovent survey. Eur Respir J 2005;25(6): 1025-1031.

2. Fauroux B, Howard P, Muir JF. Home treatment for chronic respiratory insufficiency: the situation in Europe in 1992. Eur Respir J 1994;7(9):1721-1726

3. Muir JF, Girault C, Cardinaud JP, Polu JM. Survival and long-term follow-up of tracheostomized patients with COPD treated by home mechanical ventilation. A multicenter French study in 259 patients. Chest 1994;106(1):201-209.

4. Splaingard ML, Frates RC Jr, Jefferson LS, Rosen CL, Harrison GM. Home negative pressure ventilation: report of 20 years of experience in patients with neuromuscular disease. Arch Phys Med Rehabil 1985;66(4):239-242.

5. Baydur A, Layne E, Aral H, Krishnareddy N, Topacio R, Frederick $\mathrm{G}$, Bodden $\mathrm{W}$. Long term non-invasive ventilation in the community for patients with musculoskeletal disorders: 46 year experience and review. Thorax 2000;55(1):4-11.

6. Simonds AK, Elliott MW. Outcome of domiciliary nasal intermittent positive pressure ventilation in restrictive and obstructive disorders. Thorax 1995;50(6):604-609.

7. Leger P, Bedicam JM, Cornette A, Reybet-Degat O, Langevin B, Polu JM, et al. Nasal intermittent positive pressure ventilation. Longterm follow-up in patients with severe chronic respiratory insufficiency. Chest 1994;105(1):100-105.

8. Windisch W. Impact of home mechanical ventilation on health-related quality of life. Eur Respir J 2008;32(5):1328-1336.

9. Farrero E, Prats E, Manresa F, Escarrabill J. Outcome of non-invasive domiciliary ventilation in elderly patients. Respir Med 2007; 101(6):1068-1073.

10. Zieliński J. [Morbid obesity as a cause of respiratory failure]. Pneumonol Alergol Pol 2012;80(6):555-559. Article in Polish.

11. Sturm R. Increases in morbid obesity in the USA: 2000-2005. Public Health 2007;121(7):492-496.

12. Laub M, Berg S, Midgren B, Swedish Society of Chest Medicine. Home mechanical ventilation in Sweden-inequalities within a homogenous health care system. Respir Med 2004;98(1):38-42.

13. Chailleux E, Fauroux B, Binet F, Dautzenberg B, Polu JM. Predictors of survival in patients receiving domiciliary oxygen therapy or mechanical ventilation. A 10-year analysis of ANTADIR Observatory. Chest 1996;109(3):741-749.

14. Janssens JP, Derivaz S, Breitenstein E, De Muralt B, Fitting JW, Chevrolet JC, Rochat T. Changing patterns in long-term noninvasive ventilation: a 7-year prospective study in the Geneva Lake area. Chest 2003;123(1):67-79.

15. Escarrabill J. Organisation and delivery of home mechanical ventilation. Breathe 2009;6(1):37-42.

16. Garner DJ, Berlowitz DJ, Douglas J, Harkness N, Howard M, McArdle $\mathrm{N}$, et al. Home mechanical ventilation in Australia and New Zealand. Eur Respir J 2013;41(1):39-45.

17. Cuvelier A, Muir JF. Noninvasive ventilation and obstructive lung diseases. Eur Respir J 2001;17(6):1271-1281.

18. Chu CM, Yu WC, Tam CM, Lam CW, Hui DS, Lai CK. Home mechanical ventilation in Hong Kong. Eur Respir J 2004;23(1):136141
19. Goldring J, Wedzicha J. Home NIV: results and lessons from a European survey. Eur Respir 2008;41:392-399.

20. Nasiłowski J, Szkulmowski Z, Migdał M, Andrzejewski W, Drozd W, Czajkowska-Malinowska M, et al. [Prevalence of home mechanical ventilation in Poland]. Pneumonol Alergol Pol 2010;78(6):392398. Article in Polish.

21. Midgren B, Olofson J, Harlid R, Dellborg C, Jacobsen E, Nørregaard O. Home mechanical ventilation in Sweden, with reference to Danish experiences. Respir Med 2000;94(2):135-138.

22. Duiverman ML, Bladder G, Meinesz AF, Wijkstra PJ. Home mechanical ventilatory support in patients with restrictive ventilatory disorders: a 48-year experience. Respir Med 2006;100(1):56-65.

23. Szkulmowski Z. [Home mechanical ventilation by the Sue Ryder Home Ventilation Team in Bydgoszcz]. Anestezjol Intens Ter 2003; 35(3):185-188. Article in Polish.

24. Migdał M, Szreter T, Juszko M, Jakubowska-Winecka A. Two years experience of the Polish National Centre for home mechanical ventilation in children. Eur Respir J 2002;20(38):531s.

25. Srinivasan S, Doty SM, White TR, Segura VH, Jansen MT, Davidson Ward SL, Keens TG. Frequency, causes, and outcome of home ventilator failure. Chest 1998;114(5):1363-1367.

26. Laub M, Midgren B. Survival of patients on home mechanical ventilation: a nationwide prospective study. Respir Med 2007;101(6): 1074-1078.

27. Veale D, Gonzalez-Bermejo J, Borel JC, Rida Z, Pontier S, Muir JF, et al. [Initiation of long-term non-invasive ventilation at home: current practices and expected issues. Surveys from the CasaVNI working party]. Rev Mal Respir 2010;27(9):1022-1029. Article in French.

28. McEvoy RD, Pierce RJ, Hillman D, Esterman A, Ellis EE, Catcheside $\mathrm{PG}$, et al. Nocturnal non-invasive nasal ventilation in stable hypercapnic COPD: a randomised controlled trial. Thorax 2009;64(7): 561-566.

29. Moran F, Bradley JM, Piper AJ. Non-invasive ventilation for cystic fibrosis. Cochrane Database Syst Rev 2013;(4):CD002769.

30. Rowińska-Zakrzewska E, Korzeniewska-Koseła M, Roszkowski-Śliż K. Extrapulmonary tuberculosis in Poland in the years 1974-2010. Pneumonol Alergol Pol 2013;81(2):121-129. Article in Polish.

31. Jäger L, Franklin KA, Midgren B, Löfdahl K, Ström K. Increased survival with mechanical ventilation in posttuberculosis patients with the combination of respiratory failure and chest wall deformity. Chest 2008;133(1):156-160.

32. Gustafson T, Franklin KA, Midgren B, Pehrsson K, Ranstam J, Ström K. Survival of patients with kyphoscoliosis receiving mechanical ventilation or oxygen at home. Chest 2006;130(6):1828-1833.

33. Górecka D, Jassem E, Pierzchała W, Sliwiński P, Polskie Towarzystwo Chorób Płuc (PTChP). Recommendations of the Polish Society of Lung Diseases for diagnosis and treatment of chronic obstructive pulmonary disease (COPD). Pneumonol Alergol Pol 2012; 80(3):220-254. Article in Polish.

34. Paciorek M, Korczyński P, Bielicki P, Byśkiniewicz K, Zieliński J, Chazan R. Obstructive sleep apnea in shift workers. Sleep Med 2011;12(3):274-277 